\title{
Design and Analysis of a Multiband Koch Fractal Monopole Antenna
}

\author{
${ }^{1}$ A. Ismahayati, ${ }^{1,2}$ P.J Soh, ${ }^{1}$ R.Hadibah, ${ }^{2}$ G.A.E Vandenbosch \\ ${ }^{1}$ School of Computer and Communication Engineering \\ Universiti Malaysia Perlis (UniMAP) \\ 02000 Kuala Perlis, Perlis, MALAYSIA \\ [ismahayati,pjsoh]@unimap.edu.my \\ ${ }^{2}$ ESAT-TELEMIC \\ Katholieke Universiteit Leuven \\ 3001 Leuven, BELGIUM \\ [PingJack.Soh, Guy.Vandenbosch]@esat.kuleuven.be
}

\begin{abstract}
This work presents the design and investigation of the monopole and Koch fractal antenna. The fractal concept and geometry has been used in antenna design to obtain multi-band behavior and miniaturized size, as both of these characteristics are important requirements in current antenna design trends. The aim of this paper is to evaluate the antenna performance between monopole antenna and third iteration Koch fractal antenna. Antenna properties such as reflection coefficient $\left(S_{11}\right)$, bandwidth, gain and radiation pattern are analyzed and discussed in this paper. The result shows that both antennas can operate well at respective designed resonances. However, the third iteration Koch fractal antenna is also proven to be advantageous over the planar monopole - more number of resonant frequencies, larger bandwidth and smaller size.
\end{abstract}

Keywords-antennas, multi-band antennas, fractal antennas, monopole antenna, antenna miniaturization

\section{INTRODUCTION}

Fractal shaped antennas have already been proven to have some unique characteristics that are linked to the geometrical properties of fractal. Self-similarity of fractal makes them especially suitable for multi-frequency applications. When the size of an antenna is made much smaller than the operating wavelength, theoretically, it becomes highly inefficient. Its radiation resistance decreases proportionally, along with the rapid increase of stored reactive energy.

Very recently, several antenna based on the fractal topology has been proposed and investigated. They have been applied to loops, dipoles, monopoles, patches, slots, arrays and PIFAs [13]. However, it is important to note that Koch fractal is advantageous in terms of efficiency, despite the theoretical limitation. An analysis of this aspect, against Chu's fundamental limit has been carried out in [4]. On the other hand, [5] has also concluded that fractal Minkowski loops produced low resonant frequency relative to the electrical size, besides lower side lobes [6]. Comparison of several fractal and self-similar shaped antennas are also carried out by [7]. It is also demonstrated that the Koch fractal monopole's limit in lowering resonant frequencies is a direct function of the limit in the increase of the antenna's effective volume. On the other hand, experimental investigations on this topology have also resulted in more compact, multi- and even broad-resonating structures $[8,9]$.

This work, inspired by these previous literatures, aims to investigate the effect of self-similarity on the antenna's performance parameters (reflection coefficient, bandwidth, number of resonance, radiation pattern, etc). This is carried out through a systematic parametric study, design fabrication and measurement, in comparison to previous work, which are more analytically based. A practical, planar realization is also proposed in a form of planar printed Koch monopole, with a small ground plane at the reverse side of antenna. Performance of a third iteration Koch monopole is studied in detail and compared to a conventional planar monopole. Its contributions in terms of physical parameters, especially electrical wavelength and antenna compactness are also analyzed.

\section{ANTENNA DESIGN}

The initial design of the self similar Koch monopole is listed in Fig. 1. The side dimensions of the fractals, which forms the basis of the antenna, are shown for first, second and third iterations, respectively. The zero-th element monopole antenna is labeled as $K O$. To form the first iteration $(K 1)$, the straight line transformation is scaled to one third of its original length, with the center line bent at $\theta=60^{\circ}$. The illustration of transformation is given in Fig. 2. The second (K2) and third (K3) iteration are formed by translating their previous iteration, which each side of the line with the same length.

For a conventional monopole antenna, its height, $h$, is determined by;

$$
h=\frac{\lambda}{4}
$$




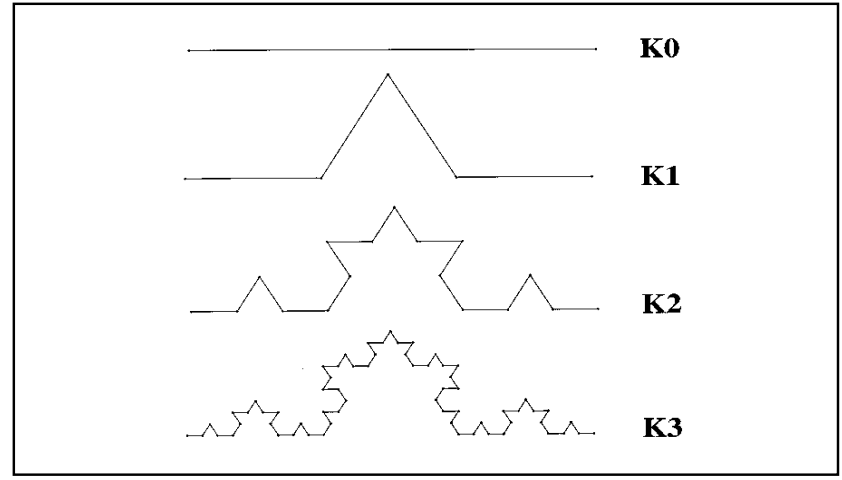

Figure 1. Koch fractal monopole from zero-th to third iteration $[4,10]$

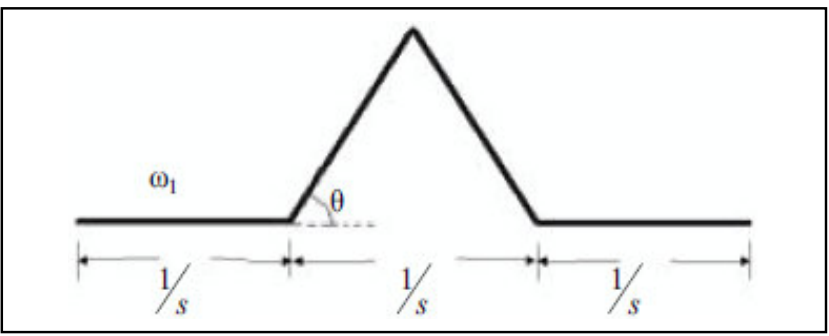

Figure 2. Transformation of the first iteration Koch fractal antenna [11]

Then from [11];

$$
\begin{aligned}
& l=h\left(\frac{4}{3}\right)^{n} \\
& s=2(1+\cos \theta)
\end{aligned}
$$

where; $h$ is the monopole antenna's height, $l$, the effective length, $n$, its iteration number, and $s$, scaling factor. Considering the stated three equations for $2.45 \mathrm{GHz}$, the calculated $h$ and $l$ is $30.6 \mathrm{~mm}$. After optimization, $l$ is equal to $44 \mathrm{~mm}$, which is slightly larger compared to proposed conventional design equation. From this dimension, the Koch fractal's first iteration is designed using the scaling factor $1 / s$, where $s$ is calculated from equation (3). The dimension of the monopole and third iteration Koch fractal is illustrated in Fig. 3.

\section{PARAMETRIC STUDY}

Prior to fabrication of the final structure, a parametric study is carried out to pre-determine the cause-effects of fabrication inaccuracies. The study is carried out on proposed structures, the zero-th iteration monopole and the third iteration Koch monopole. Parameters investigated are critical parameters: (1) the length of the substrate $\left(L_{\mathrm{s}}\right) ;(2)$ Length of the ground plane $\left(L_{\mathrm{g}}\right)$; (3) width of the substrate, $W_{\mathrm{s}}$, and (4) thickness of the monopole trace line $(t)$. All the investigations have been carried out using CST Microwave Studio software.

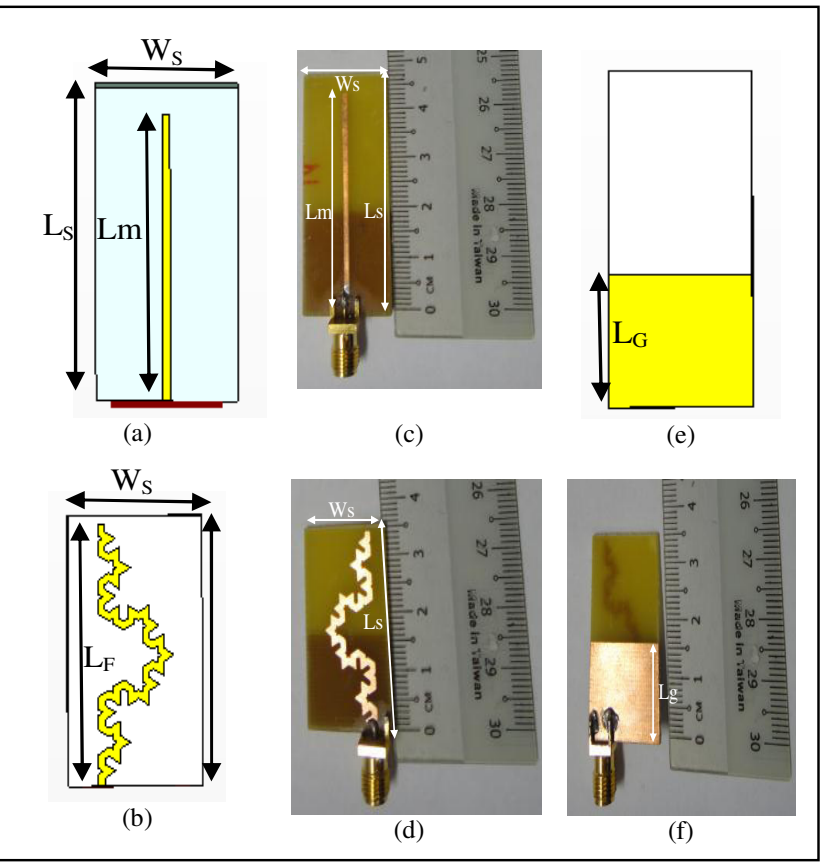

Figure 3. Simulated dimension of the (a) monopole antenna (a) Koch fractal monopole; (c) fabricated monopole; (d) fabricated Koch fractal monopole (e) simulated common ground plane; (f) fabricated common ground plane

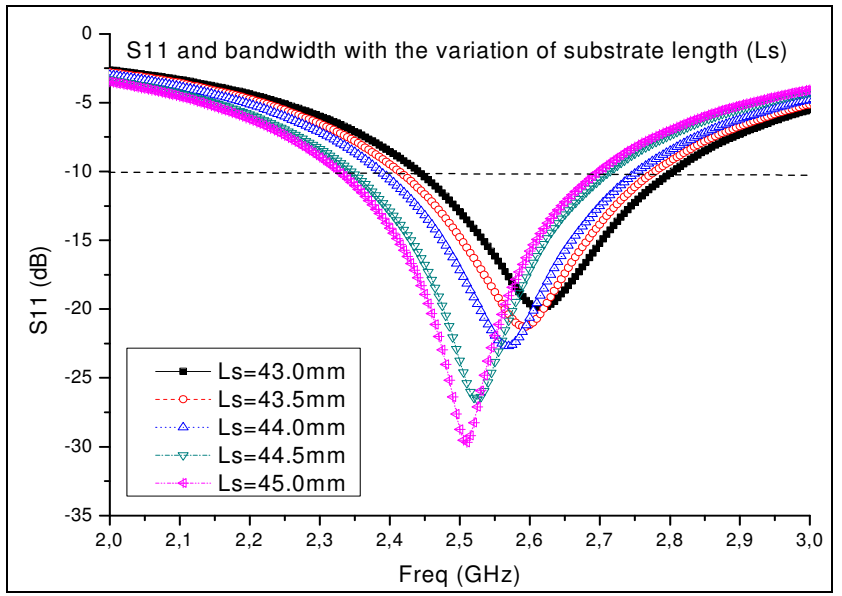

Figure 4. $S_{11}$ and bandwidth with the variation of the planar monopole's substrate length $\left(L_{\mathrm{s}}\right)$

The first investigated parameter for the planar monopole structure is its substrate length $\left(L_{\mathrm{s}}\right)$. Its effects on the antenna's $S_{11}$ and bandwidth in $0.5 \mathrm{~mm}$ and $1 \mathrm{~mm}$ steps are shown in Fig. 4. It can be observed that with an increasing length of $L_{\mathrm{s}}$, the resonant frequency is shifting downwards. At the same time, the improved matching has also improved $S_{11}$, shown by its decreasing negative values. Bandwidth, on the other hand, is maintained between $360 \mathrm{MHz}$ and $368 \mathrm{MHz}$. Next, the width of the substrate $\left(W_{\mathrm{s}}\right)$ is investigated. It is seen that a slight upwards shift of the resonant frequency and $S_{11}$ occurred with the increase in width. This is due to the change in impedance 
matching, which is quite minimal compared to the one caused by its length, $L_{\mathrm{s}}$. Bandwidth is almost constant even with the shift of center frequency, and all $S_{11}$ are at a satisfactory level below $-10 \mathrm{~dB}$. All the result is shown in Fig. 5.

Changes caused by the next parameter, the ground plane length $\left(L_{\mathrm{g}}\right)$, is more significant than the previous two. Looking at Fig. 6 , the choice of $L_{\mathrm{g}}$ plays an important part in determining the depth of the $S_{11}$ curve. A change of $2 \mathrm{~mm}$, from $19 \mathrm{~mm}$ to $21 \mathrm{~mm}$ is enough to degrade its reflection coefficient by more than $30 \mathrm{~dB}$. Variation in the monopole's line thickness, $t$, meanwhile, also did not cause much impedance change that is enough to significantly degrade the performance of the planar monopole. This can be seen in Fig. 7 , which indicates that an increase of $0.1 \mathrm{~mm}$ in thickness shifts the center frequency downwards, with an improved reflection matching.

In summary, only two parameters significantly affect the monopole structure. Thus, in the analysis of the Koch fractal monopole, only these two critical parameters are analyzed for changes in $S_{11}$ and bandwidth. The third iteration Koch fractal monopole generally produced three resonant frequencies, at $2.4 \mathrm{GHz}, 5.8 \mathrm{GHz}$ and $7 \mathrm{GHz}$. Variation of $L_{\mathrm{s}}$ did not affect the resonance at $2.4 \mathrm{GHz}$, but changes the impedance match and $S_{11}$ at the other two higher frequencies. The $S_{11}$ in between the two resonances has also been slightly affected. The longer $L_{\mathrm{s}}$ is, the smaller the bandwidth at both $5.8 \mathrm{GHz}$ and $7 \mathrm{GHz}$, but with improved $S_{11}$ s. This can be observed in Fig. 8. On the other hand, changes for $L_{\mathrm{g}}$ has caused the fractal monopole produce an upwards center frequency shift at $2.4 \mathrm{GHz}$. Changes are mostly significant at the two higher frequency bands. An increased ground plane length $L_{\mathrm{g}}$ from $13 \mathrm{~mm}$ to 17 $\mathrm{mm}$ causes the antenna to have closer center frequencies. In other words, the two resonances at $5.8 \mathrm{GHz}$ and $7 \mathrm{GHz}$ are seen to be merging, forming a broad, single resonant bandwidth, with the increase of $L_{\mathrm{g}}$. However, this merger is complemented by a decrease in its $S_{11}$ matching values, which is shown in Fig. 9.

\section{RESUlT AND DisCUSSION}

Measured and simulated results for the planar monopole and Koch fractal antenna are presented in this section. Both antennas have been fabricated on an FR-4 board (with dielectric constant, $\epsilon_{\mathrm{r}}=4.7$, and substrate thickness, $t=1.6$ $\mathrm{mm}$ ). Fig. 10 illustrates $S_{11}$ comparison between the planar monopole and the third iteration Koch fractal antenna. Both measured antennas operate well in $2.45 \mathrm{GHz}$ frequency range. The measured monopole antenna resonates at a single frequency, while three resonance frequencies are achieved by the third iteration Koch fractal antenna. This shows that the number of resonant frequencies relates to the increase in the fractal iteration number. Numerical details of the results are summarized in Table 1. For planar monopole, a simulated bandwidth of about $400 \mathrm{MHz}$ is achieved. When measured, the $300 \mathrm{MHz}$ bandwidth at $2.45 \mathrm{GHz}$ range is divided into two smaller ranges. On the other hand, the fractal Koch monopole generated $720 \mathrm{MHz}$ of bandwidth at this frequency, whereas

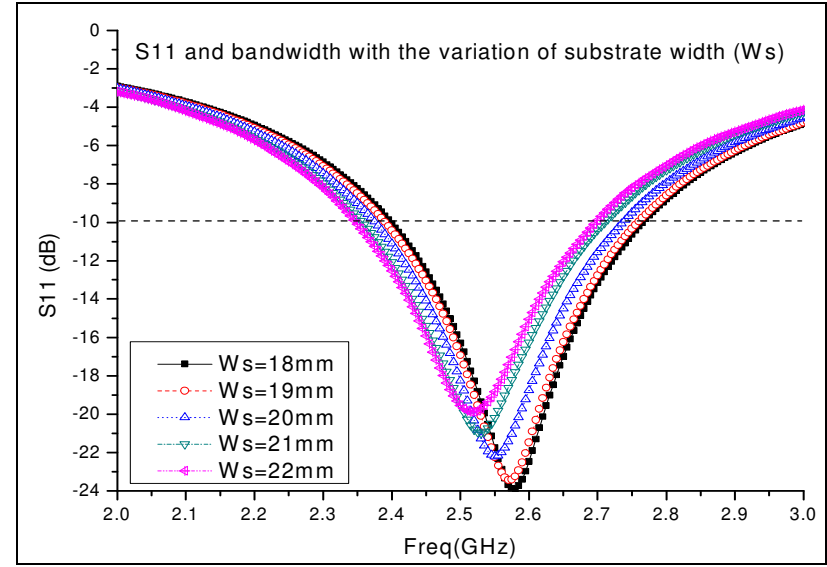

Figure 5. $S_{11}$ and bandwidth with the variation of the planar monopole's substrate width $\left(W_{\mathrm{s}}\right)$

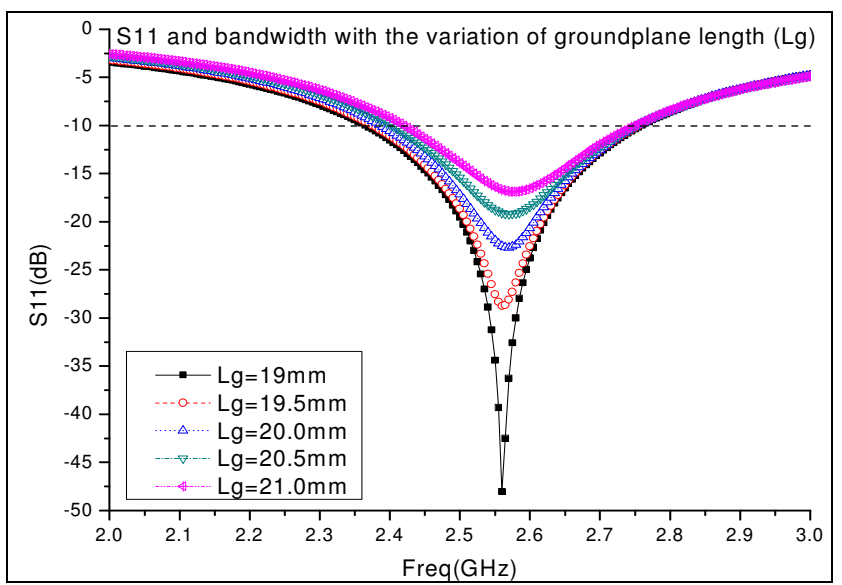

Figure 6. $S_{11}$ and bandwidth with the variation of the planar monopole's ground plane length $\left(L_{\mathrm{g}}\right)$

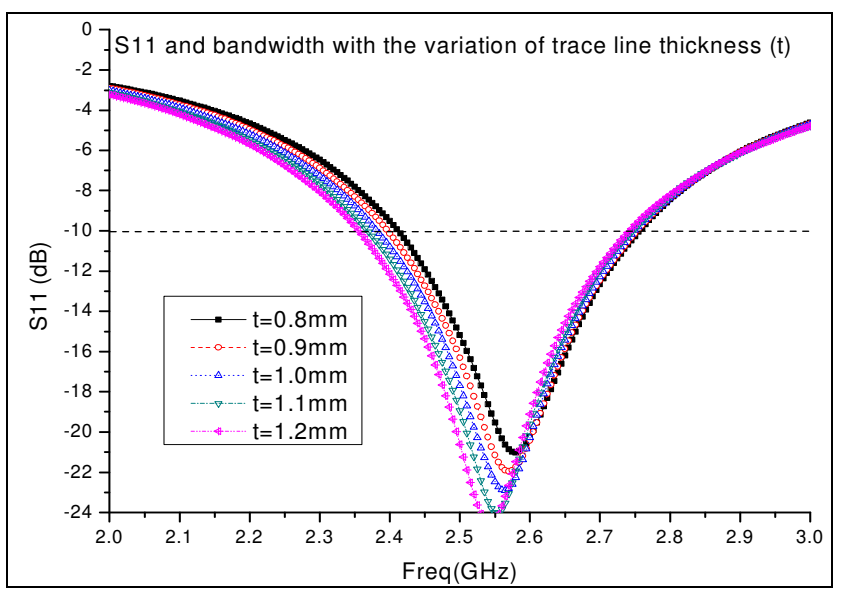

Figure 7. $S_{11}$ and bandwidth with the variation of the planar monopole's line thickness $(t)$ 


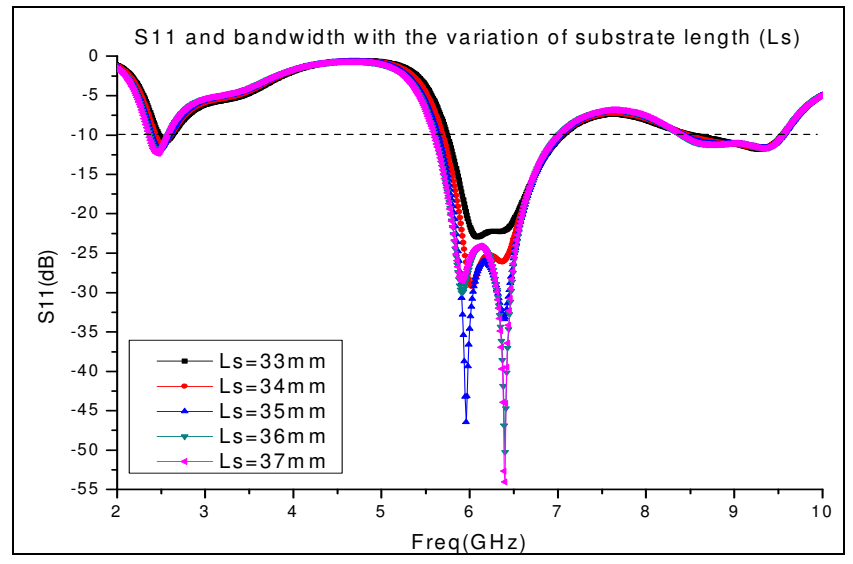

Figure 8. $S_{11}$ and bandwidth with the variation of the Koch fractal monopole's substrate length $\left(L_{\mathrm{s}}\right)$

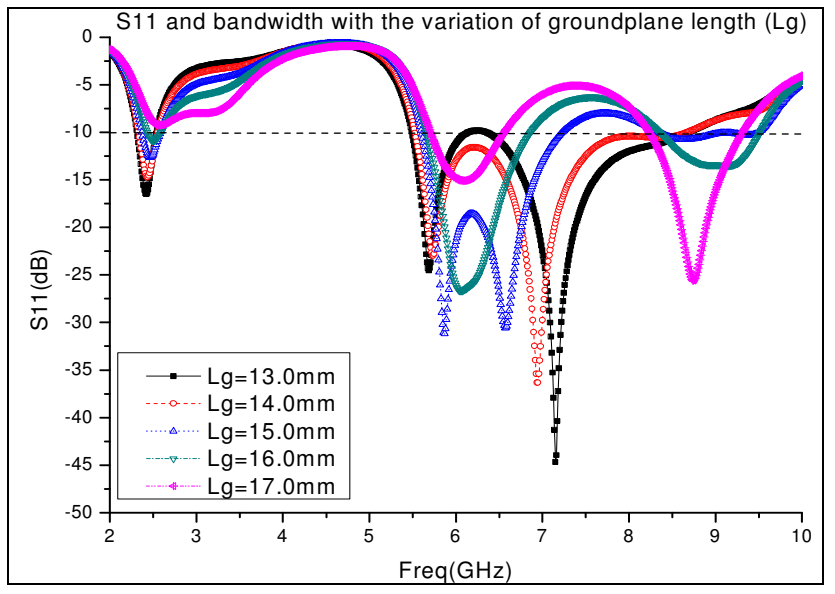

Figure 9. $S_{11}$ and bandwidth with the variation of the Koch fractal monopole's ground plane length $\left(L_{\mathrm{g}}\right)$

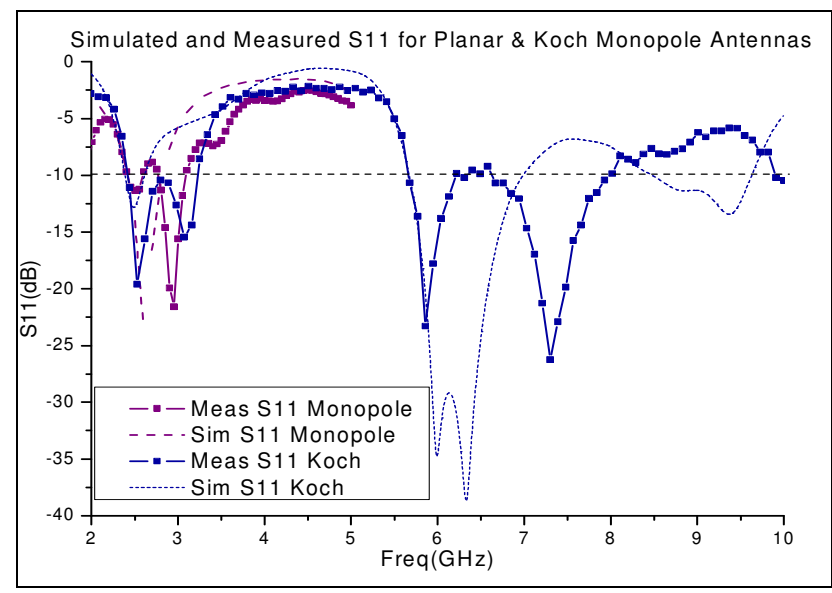

Figure 10. Simulated and measured $S_{11}$ and bandwidth for the planar monopole and Koch fractal monopole antennas.

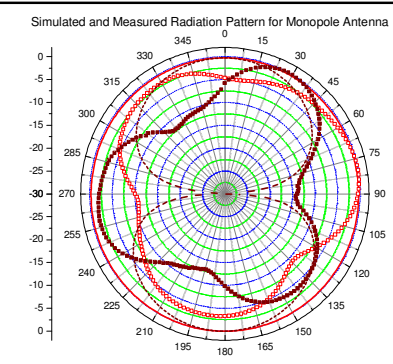

(a)

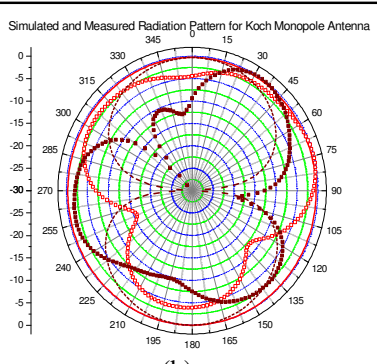

(b)
Figure 11. Radiation patterns of the investigated antennas (a) Planar Monopole; (b) Koch Monopole (Legend: (-) Simulated Eplane; (ロ)Measured Eplane; (---)Simulated Hplane; ( $\square$ )Measured Hplane.)

TABLE I. SUMMARY OF THE ANTENNA DIMENSIONS AND PERFORMANCE

\begin{tabular}{|c|c|c|c|c|}
\hline \multirow{2}{*}{ Antenna } & \multicolumn{2}{|c|}{ Planar Monopole } & \multicolumn{2}{|c|}{ Fractal Monopole } \\
\hline & Simulated & Measured & Simulated & Measured \\
\hline$L(\mathrm{~mm})$ & 44.0 & 44.0 & 34.0 & 34.0 \\
\hline$t(\mathrm{~mm})$ & 1.0 & 1.0 & 1.0 & 1.0 \\
\hline$L_{\mathrm{S}}(\mathrm{mm})$ & 48.0 & 48.0 & 35.0 & 35.0 \\
\hline$L_{\mathrm{g}}(\mathrm{mm})$ & 20.0 & 19.0 & 16.0 & 15.5 \\
\hline$W_{\mathrm{S}}(\mathrm{mm})$ & 20.0 & 20.0 & 20.0 & 19.5 \\
\hline$f_{\mathrm{c}}(\mathrm{GHz})$ & 2.600 & 2.55 & $\begin{array}{l}2.49 \\
6.33 \\
9.06\end{array}$ & $\begin{array}{l}2.45 \\
6.85 \\
9.82\end{array}$ \\
\hline $\begin{array}{l}S_{11} \text { at } 2.45 \mathrm{GHz} \\
(\mathrm{dB})\end{array}$ & -11.68 & -11.06 & -12.33 & -11.10 \\
\hline $\operatorname{Min} S_{11}(\mathrm{~dB})$ & -22.78 & -21.59 & $\begin{array}{l}-12.81 \\
-33.10 \\
-13.44\end{array}$ & $\begin{array}{l}-19.61 \\
-23.31 \\
-26.24\end{array}$ \\
\hline $\begin{array}{l}\text { 10dB limit } \\
\text { (lower) }(\mathrm{GHz}) f_{\mathrm{L}}\end{array}$ & 2.42 & $\begin{array}{l}2.41 \\
2.80\end{array}$ & $\begin{array}{l}2.39 \\
5.67 \\
8.48\end{array}$ & $\begin{array}{l}2.44 \\
5.68 \\
9.68\end{array}$ \\
\hline $\begin{array}{l}\text { 10dB limit } \\
\text { (upper) }(\mathrm{GHz}) f_{\mathrm{H}}\end{array}$ & 2.83 & $\begin{array}{l}2.46 \\
2.80\end{array}$ & $\begin{array}{l}2.62 \\
7.00 \\
9.63\end{array}$ & $\begin{array}{c}3.16 \\
8.02 \\
10.00\end{array}$ \\
\hline $\begin{array}{l}\text { Bandwidth } \\
(\mathrm{MHz})\end{array}$ & 409 & $\begin{array}{c}50 \\
250\end{array}$ & $\begin{array}{c}230 \\
1318 \\
1154 \\
\end{array}$ & $\begin{array}{c}720 \\
2340 \\
360 \\
\end{array}$ \\
\hline Gain $(\mathrm{dB})$ & 2.38 & - & 2.12 & - \\
\hline Electrical Length & $0.36 \lambda$ & $0.36 \lambda$ & $0.28 \lambda$ & $0.28 \lambda$ \\
\hline
\end{tabular}

simulation only predicted $230 \mathrm{MHz}$ of bandwidth. Another two resonances are predicted by the simulation, at $6 \mathrm{GHz}$ and 9 $\mathrm{GHz}$ for this antenna, respectively. However, the measured prototype showed that these two resonances have experienced frequency up-shifting to $6.85 \mathrm{GHz}$ and $9.82 \mathrm{GHz}$, respectively.

In Fig. 11, both antennas generated similar radiation patterns at both E- and H-planes. Gains produced by both antennas are also typical of a monopole antenna, which is between $2 \mathrm{~dB}$ and $2.5 \mathrm{~dB}$. The gain of planar monopole antenna is higher, due to the inexistence of bent trace lines, which is likely to cause power loss. 


\section{CONCLUSION}

Two topologies of planar monopoles with small ground plane has been proposed and investigated. Both antennas are able to operate well at multiple resonant frequencies with satisfactory performance. Measurement results further verified this finding. The usage of the Koch fractal topology, in particular, has managed to enhance the antenna in terms of additional higher resonance frequencies and broad bandwidth. At the same time, it also contributed to space saving through electrical length shortening, by more than $20 \%$. These size compactness and multi-resonant antenna behaviors are particularly significant, in line with the miniaturization of today's electronic devices.

\section{ACKNOWLEDGMENT}

The authors would like to acknowledge Universiti Malaysia Perlis (UniMAP) PCB Fabrication Lab and A.A.M Ezanuddin for the technical support which enabled the production of this article.

\section{REFERENCES}

[1] N. A. Saidatul, A. A. H. Azremi, R. B. Ahmad, P. J. Soh, and F. Malek, "Multiband fractal planar inverted F antenna (F-PIFA) for mobile phone application," Progress in Electromagnetic Research (PIER), vol. 14, pp. 127-148, 2009.

[2] P. J. Soh, G. A. E. Vandenbosch, S. L. Ooi, and M. R. N. Husna, "Wearable dual-band Sierpinski fractal PIFA using conductive fabric," Electronics Letters, vol. 47, pp. 365-367, 2011.
[3] S. N. Shafie, I. Adam, and P. J. Soh, "Design and Simulation of a Modified Minkowski Fractal Antenna for Tri-Band Application," in Mathematical/Analytical Modelling and Computer Simulation (AMS), 2010 Fourth Asia International Conference on, 2010, pp. 567-570.

[4] C. P. Baliarda, J. Romeu, and A. Cardama, "The Koch monopole: a small fractal antenna," Antennas and Propagation, IEEE Transactions on, vol. 48, pp. 1773-1781, 2000.

[5] S. R. Best, "On the resonant properties of the Koch fractal and other wire monopole antennas," Antennas and Wireless Propagation Letters, IEEE, vol. 1, pp. 74-76, 2002.

[6] A. Sundaram, M. Maddela, and R. Ramadoss, "Koch-Fractal FoldedSlot Antenna Characteristics," Antennas and Wireless Propagation Letters, IEEE, vol. 6, pp. 219-222, 2007.

[7] S. R. Best, "On the performance properties of the Koch fractal and other bent wire monopoles," Antennas and Propagation, IEEE Transactions on, vol. 51, pp. 1292-1300, 2003.

[8] B. Mirzapour and H. R. Hassani, "Size reduction and bandwidth enhancement of snowflake fractal antenna," Microwaves, Antennas \& Propagation, IET, vol. 2, pp. 180-187, 2008.

[9] M. N. A. Karim, M. K. A. Rahim, H. A. Majid, O. B. Ayop, M. Abu, and F. Zubir, "Log periodic fractal Koch antenna for UHF band applications," Progress in Electromagnetic Research (PIER), vol. 100, pp. 201-218, 2010

[10] S. R. Best, "A discussion on the significance of geometry in determining the resonant behavior of fractal and other non-Euclidean wire antennas," Antennas and Propagation Magazine, IEEE, vol. 45, pp. 9-28, 2003.

[11] K. J. Vinoy, J. K. Abraham, and V. K. Varadan, "On the relationship between fractal dimension and the performance of multi-resonant dipole antennas using Koch curves," Antennas and Propagation, IEEE Transactions on, vol. 51, pp. 2296-2303, 2003. 